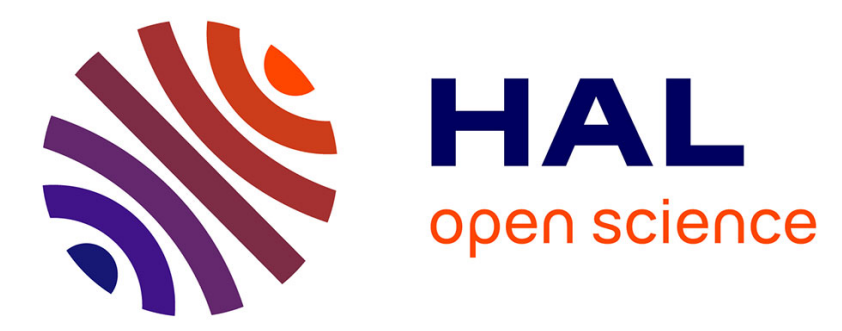

\title{
Mass transfer in a membrane aerated biofilm
}

Charlotte Picard, Sébastien Logette, Jean-Christophe Schrotter, Pierre Aimar, Jean-Christophe Remigy

\section{To cite this version:}

Charlotte Picard, Sébastien Logette, Jean-Christophe Schrotter, Pierre Aimar, Jean-Christophe Remigy. Mass transfer in a membrane aerated biofilm. Water Research, 2012, Vol. 46, pp. 4761-4769. 10.1016/j.watres.2012.05.056 . hal-00873332

\section{HAL Id: hal-00873332 \\ https://hal.science/hal-00873332}

Submitted on 15 Oct 2013

HAL is a multi-disciplinary open access archive for the deposit and dissemination of scientific research documents, whether they are published or not. The documents may come from teaching and research institutions in France or abroad, or from public or private research centers.
L'archive ouverte pluridisciplinaire HAL, est destinée au dépôt et à la diffusion de documents scientifiques de niveau recherche, publiés ou non, émanant des établissements d'enseignement et de recherche français ou étrangers, des laboratoires publics ou privés. 


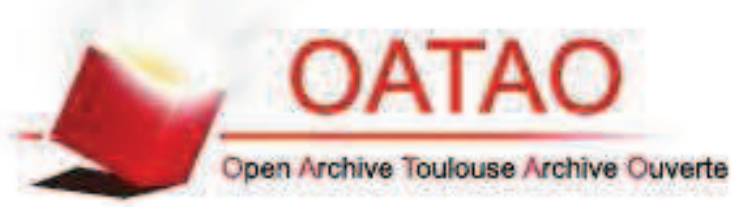

\section{Open Archive TOULOUSE Archive Ouverte (OATAO)}

OATAO is an open access repository that collects the work of Toulouse researchers and makes it freely available over the web where possible.

This is an author-deposited version published in : http://oatao.univ-toulouse.fr/ Eprints ID : 9720

To link to this article : DOI:10.1016/j.watres.2012.05.056

URL : http://dx.doi.org/10.1016/j.watres.2012.05.056

\section{To cite this version :}

Picard, Charlotte and Logette, Sébastien and Schrotter, Jean-

Christophe and Aimar, Pierre and Remigy, Jean-Christophe Mass

transfer in a membrane aerated biofilm. (2012) Water Research, Vol. 46 (n 15). pp. 4761-4769. ISSN 0043-1354

Any correspondance concerning this service should be sent to the repository administrator: staff-oatao@1istes-diff.inp-toulouse.fr 


\title{
Mass transfer in a membrane aerated biofilm
}

\author{
C. Picard ${ }^{a, b, c, *}$, S. Logette ${ }^{c}$, J.C. Schrotter ${ }^{c}$, P. Aimar ${ }^{a, b}$, J.C. Remigy ${ }^{a, b}$ \\ ${ }^{a}$ Université de Toulouse, INPT, UPS, Laboratoire de Génie Chimique, 118 Route de Narbonne, F-31062 Toulouse, France \\ ${ }^{\mathrm{b}}$ CNRS, Laboratoire de Génie Chimique, F-31062 Toulouse, France \\ ${ }^{\mathrm{c}}$ Veolia Environnement, Recherche \& Innovation, Chemin de la Digue, BP 76, 78603 Maisons-Laffitte, France
}

Keywords:

Mass transfer

Convection

Membrane aerated biofilm

Wastewater treatment

Effective diffusivity

\begin{abstract}
A B S T R A C T
We present experimental results of mass transfer of a non reactive tracer gas (neon) measured in aerobic heterotrophic biofilm developed from activated sludge. Biofilms are grown in various hydrodynamic conditions and the effective diffusivity is used to quantify the mass transfer through the biofilm. Beyond some cross-flow conditions, the effective diffusivity through the biofilm seems larger than in the bulk. This can be explained by a dispersion generated by convection inside the biofilm, as supported by an analytical flow model and in accordance to the numerical simulation proposed by Aspa et al. (2011).
\end{abstract}

\section{Introduction}

Over the last decades, process intensification of wastewater treatment has given birth to the development of immobilized biomass reactors, mainly because such techniques allow to decouple hydraulic residence times of the biomass and the effluent. Membrane Bioreactors (MBR) are one of the most prominent recent innovations, which combine advantages of bulk stirred reactors to the selectivity of pressure driven membrane processes. One of their main disadvantages is membrane fouling, which is particularly heavy at high concentrations in biomass. Not only the flux through the reactor but also the retention of small species, including those with a toxic effect on the biomass, are altered by membrane fouling and require periodic cleaning procedures. For this reason, reactors based on biofilms are another way of immobilizing biomass, investigated since the beginning of the 60 's.
In such conventional biofilms grown on a massive surface, both substrates transfer from the bulk to the inner parts of the biofilm by diffusion. In the case of aerobic reactions, the gradient of oxygen concentration is actually limited by its solubility in water and aqueous solutions, and there is not much that can be made about that. Emanuelsson and Livingston (2004) have therefore replaced oxygen by nitrates for the removal of toluene from effluents, but this option does not apply to any type of reaction.

A way to enhance the transfer of oxygen to the biofilm is to directly feed the latter with gaseous oxygen (or any other convenient substrate) through a porous membrane located on one side of the biofilm, whereas soluble substrates are transferred by diffusion from the liquid (generally aqueous) phase circulated along the other side of the biofilm. Substrates are then in counter-diffusion inside the biofilm. Several studies show the advantages of such configurations. As for an

\footnotetext{
* Corresponding author. Université de Toulouse, INPT, UPS, Laboratoire de Génie Chimique, 118 Route de Narbonne, F-31062 Toulouse, France. Tel.: 33663722050 .
} 
example, Terada et al. (2006), LaPara et al. (2006) or Matsumoto et al. (2007) have studied the elimination of ammonia from effluents by Membrane Aerated Biofilms Reactors (MABR), in which a same biofilm is stratified into nitrifying at the basis of the biofilm and denitrifying sections at the upper part of the biofilm. MABR's have also been considered for the mere removal of COD from waste waters (Pankhania et al., 1999). Those reactors are also used by the group of Rittmann who replace oxygen in the gas phase by hydrogen, so they are capable of overcoming the low solubility of hydrogen in water and to control the transfer of this gas which is absolutely necessary for obvious safety reason. With those hydrogen-fed membrane biofilm reactor's, they explore reduction reactions which are very seldom considered in water treatment (Lee and Rittmann, 2002; Nerenberg et al., 2007; Chung et al., 2007).

Several studies give evidence that hydrodynamics impact mass transfer from fluid phases to the biofilm and through the biofilm (Beyenal and Lewandowski, 2000, 2002; Garcia Lopez et al., 2003). Stoodley et al. (1994) video taped the convection flow inside the biofilm and around the bacterial clusters. The part played by this convection on the global bioreactions is however not clear, most probably since any change in the hydrodynamics induces changes in the biofilm morphology, dry matter and bioactivity. De Beer and Stoodley (1995) showed that convective transport within a biofilm increased locally when increasing the flow rate above the biofilm. However, Melo (2005) reports a decrease in relative diffusivity when increasing the cross-flow in turbulent regime. Combining these observations suggests that beyond a minimum value of cross-flow, convection plays a role in mass transfer inside the biofilm, whereas beyond another threshold (a maximum, that one), convective transfer decreases. It is now well established that biofilms adapted their internal structure in function of the shear stress (Kugaprasatham et al., 1992; Kwok et al., 1998). This scheme is supported by Beyenal and Lewandowski (2000) who find a decrease of diffusivity with the increase in axial Reynolds number outside the biofilm and observe an arrangement of the internal structure of the biofilm for Reynolds number larger than 6000 .

Aspa et al. (2011) have recently released a numerical study of dispersive transport within a biofilm. They assume the bacterial clusters can be modeled as cylinders located in a periodic arrangement, their main axis being normal to the base of the biofilm. They show that in an axial convective flow (parallel to the main biofilm surface), mass transfer is diffusive and maybe dispersive in a radial direction if the Peclet number in the biofilm (Pe), defined in Eq. (1), is larger than a given transition value $\left(\mathrm{Pe}_{\mathrm{t}}\right)$.
$\mathrm{Pe}=\frac{v \cdot l}{D_{\mathrm{w}}}$

Where $v$ is the average convective velocity in the biofilm $\left(\mathrm{m} \mathrm{s}^{-1}\right)$, lis the hydraulic diameter of the channels in the biofilm $(\mathrm{m})$ and $D_{\mathrm{w}}$ is the diffusion coefficient in bulk water $\left(\mathrm{m}^{2} \mathrm{~s}^{-1}\right)$.

These results by Aspa et al. (2011) may explain why in some conditions any change in the hydrodynamics would have no impact on mass transfer within the biofilm, hence we could assume on the rates of reaction, whereas in others (namely beyond the $\mathrm{Pe}_{t}$ ) mass transfer within the biofilm is tightly linked to the reactor hydrodynamics.

Most of the experiments from literature have been studied for conventional biofilm. Little is known about the structure and mass transfer in membrane aerated biofilm, whereas the counter-diffusion of substrates makes the biofilm grow differently than in conventional biofilm: starting from the basis or the middle of the biofilm instead of the upper part of the biofilm.

The present work is an experimental study of mass transfer in a radial direction (normal to the biofilm main surface) of a biofilm and provides experimental data which support Aspa's predictions in the case of a mixed heterotrophic microorganism culture grown on a porous membrane.

\section{Material and methods}

\subsection{Experimental rig}

An experimental set up has been designed for the present study. It is made of five experimental cells in parallel. The experimental cell, made of stainless steel, is a rectangular channel of $500 \mathrm{~mm} \times 100 \mathrm{~mm}$ internal dimensions on the liquid side. This is also the actual size of the biofilm. Its thickness can be adjusted by using various spacers (from 6 to $12 \mathrm{~mm}$ ), as specified in Table 1. Each cell has three parts: the liquid channel; the membrane and its support and the gas compartment.

For a better distribution of the liquid, entrance and exit ports have been machined in the stainless steel plate as shown in Fig. 1. A glass window in the liquid side shell allows to observe the biofilm. Membranes are supported by a stainless steel grid (open area: 22\%) and they separate the liquid phase from the gas phase. The gas compartment is $510 \mathrm{~mm} \times 96 \mathrm{~mm} \times 2 \mathrm{~mm}$ in internal dimensions.

The flows through the five cells in parallel can be set independently from each other. Different hydrodynamic conditions could be used in parallel (experiments 2.1 and 2.2).

Table 1 - Parameters of the five experiments reported in this paper (Picard, 2011).

\begin{tabular}{|c|c|c|c|c|c|}
\hline \multirow[t]{2}{*}{ Run \# } & \multirow[t]{2}{*}{1} & \multicolumn{2}{|c|}{2} & \multirow[t]{2}{*}{3} & \multirow[t]{2}{*}{4} \\
\hline & & Condition 1 & Condition 2 & & \\
\hline Channel thickness (mm) & 8 & 8 & 8 & 6 & 10 \\
\hline Liquid flow rate $\left(\mathrm{L} \cdot \mathrm{h}^{-1}\right)$ & 293 & 293 & 100 & 487 & 457 \\
\hline Reynolds number & 1880 & 1880 & 643 & 3190 & 2885 \\
\hline Shear stress $(\mathrm{Pa})$ & $6.1 \times 10^{-2}$ & $6.1 \times 10^{-2}$ & $2.1 \times 10^{-2}$ & $18 \times 10^{-2}$ & $6.1 \times 10^{-2}$ \\
\hline
\end{tabular}




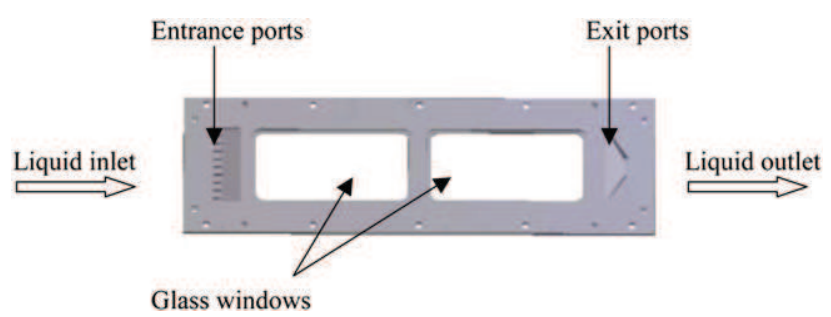

Fig. 1 - Diagrammatic representation of the inside of a cell on the liquid side (Picard, 2011).

If required, the system can be operated with less than five cells, as described later. In experiments 3 and 4, we used three of the five cells. A diagrammatic view of the experimental setup is shown in Fig. 2.

\subsection{Membranes}

The flat sheet membranes supplied by Membrana (Wuppertal, Germany) are porous and made of polypropylene (Accurel ${ }^{\circledR}$ ). They are $92.4 \mu \mathrm{m}$ thick with nominal pore sizes of $0.1 \mu \mathrm{m}$.

\subsection{Experimental conditions}

A combination of recirculation flow rates and spacers thicknesses allow to cover a broad range of Reynolds number and of wall shear stress. The parameters of the five experiments reported in this paper are given in Table 1. The gas flow through each cell is limited to $1.5 \mathrm{~mL} \mathrm{~min}^{-1}$ and contains oxygen $(20 \%)$ and nitrogen $(80 \%)$.

We used neon as a tracer to measure the transfer from the liquid phase to the gas compartment through the biofilm and the membrane. For this the liquid is saturated in neon by circulating through one of the cells used as a membrane gas/ liquid contactor fed with pure neon in the gas phase. Thanks to the recirculation circuit, all other cells are exposed to the same neon concentration in the liquid phase.

\subsection{Mass transfer characterization}

The flux of neon through the biofilm is calculated from the difference in neon concentrations and flow rates (gas flow meter: BROOKS 5850TR) at the inlet and outlet of the gas phase. The neon concentration in the liquid phase is needed to determine the global mass transfer coefficient (Eq. (2)) and is obtained by first equilibrating a known volume of this liquid against a known volume of nitrogen at a given temperature. The neon is then analyzed in its nitrogen sample by Gas Phase Chromatography (GC 450, Varian), fitted with a thermal conductivity detector. The concentration in the liquid sample is then calculated by applying the Henry's law. The flux of neon is used to determine the global mass transfer coefficient $\mathrm{K}_{\mathrm{G}}$ through the system \{liquid, biofilm, membrane, gas\} which is calculated using Eqs. (2)-(4) as proposed by Gabelman and Hwang (1999):

$K_{\mathrm{G}}=\frac{\Phi_{\text {transferred }}}{\Delta \mathrm{C}_{\ln } \cdot \mathrm{A}_{\mathrm{m}}}$

with $\Delta C_{\ln }=\frac{\Delta C_{i}-\Delta C_{o}}{\ln \left(\frac{\Delta C_{i}}{\Delta C_{0}}\right)}$

$\Delta C=C_{G}-C_{L}^{*}$

Where $\Phi_{\text {transferred }}$ is the flux of neon transferred through the biofilm from the liquid phase to the gas phase, $A_{m}$ is the membrane area, $\Delta C$ is a concentration difference of neon across the biofilm, and subscripts $i$ and o refer to "inlet" and

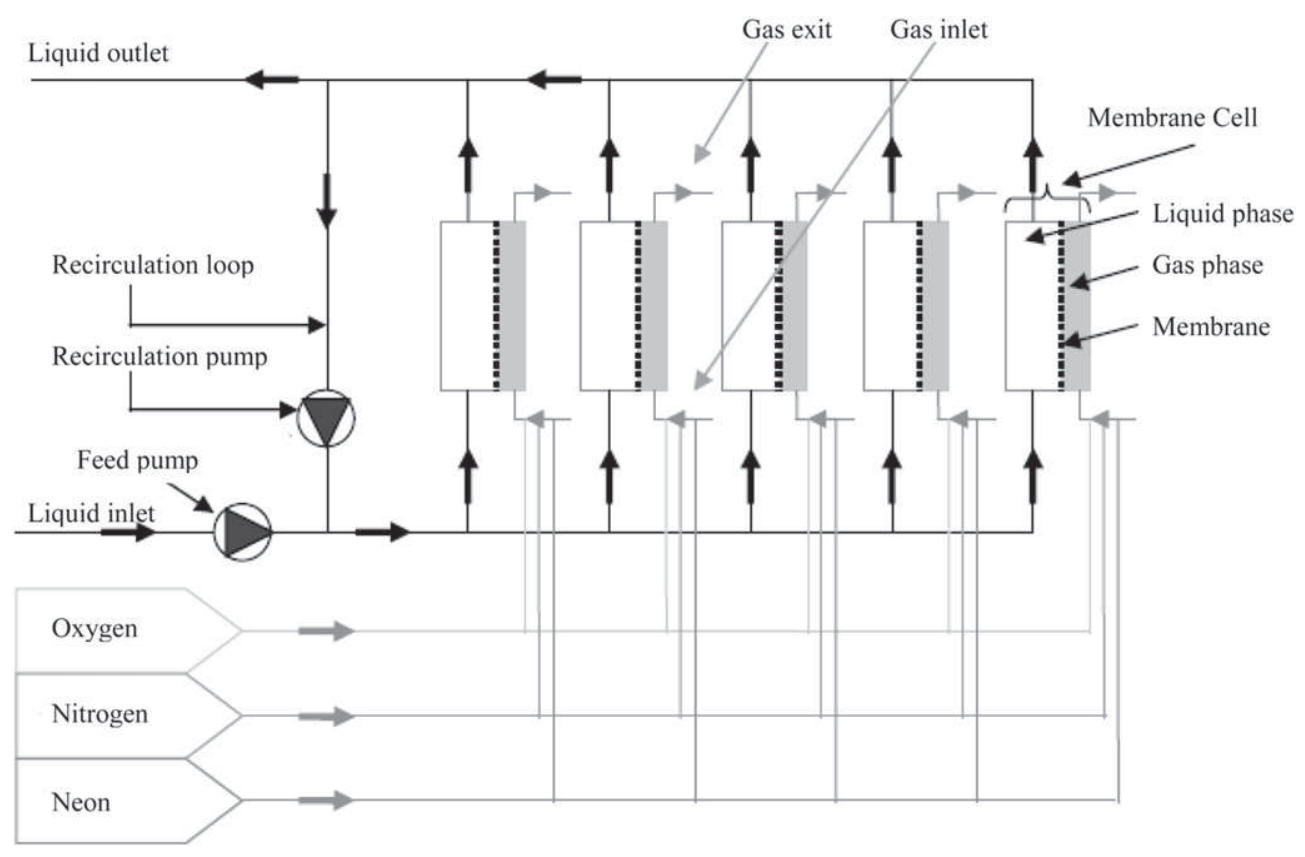

Fig. 2 - Diagrammatic view of the experimental set-up used in the present study. Five cells can be run in parallel. A circulation pump allows the cross flow to be adjusted independently from the feed rate (Picard, 2011). 
"outlet" of the membrane contactor respectively. $C_{G}$ is the concentration of neon in the gas phase, $\mathrm{C}_{\mathrm{L}}^{*}$ is the concentration of neon in the liquid phase in equilibrium with the gas phase. $\mathrm{K}_{\mathrm{G}}$ is an average mass transfer, taking into account the biofilm and hydrodynamics heterogeneity over the whole membrane area.

\subsection{Biofilm}

Before any experiment, an activated sludge collected in a wastewater treatment plant (Brax, France) and diluted in a feeding solution, is circulated in the experimental set up without any additional feeding, but with oxygen and nitrogen circulating in the gas compartments. The biofilm then starts growing on the membranes. After $24 \mathrm{~h}$, the biofilms are fed with a solution containing $1.35 \mathrm{~g} \mathrm{~L}^{-1} \mathrm{COD}$. The feed flow rate is adjusted in such a way that the COD load of the reactor is constant throughout the experiments, and equals to $50 \mathrm{mg} \mathrm{L}^{-1} \mathrm{~h}^{-1}$. Nitrogen is sparged in the feed solution. The organic carbon source is sodium acetate and the minerals are adapted from Syron and Casey (2008) and Bougard et al. (2006). The feed composition is given in Table 2.

\subsection{Biofilm characterization}

From a mass transfer point of view, a definition of the biofilm thickness can be the average thickness of the stagnant (biomass + water) laying on the surface. For this reason, we decided to adapt a method described by Wäsche et al. (2002) to determine the biofilm thickness. The flat sheet membrane with the developed biofilm was cut in 18 coupons of known length and width. For each coupon, the excess of water on the biofilm was drained by inclining the coupon for $30 \mathrm{~min}$. We

\begin{tabular}{|c|c|c|}
\hline Products & $\begin{array}{c}\text { Concentration } \\
\left(\mathrm{g} \cdot \mathrm{L}^{-1}\right)\end{array}$ & $\begin{array}{c}\text { Concentration } \\
\left(\mathrm{mol}^{\left.-\mathrm{L}^{-1}\right)}\right.\end{array}$ \\
\hline $\mathrm{CH}_{3} \mathrm{COONa}$ & 1.73 & $21.1 \times 10^{-3}$ \\
\hline $\mathrm{NaCl}$ & 0.25 & $4.28 \times 10^{-3}$ \\
\hline EDTA & 0.25 & $0.85 \times 10^{-3}$ \\
\hline$\left(\mathrm{NH}_{4}\right) \mathrm{SO}_{4}$ & 1.00 & $7.57 \times 10^{-3}$ \\
\hline $\mathrm{Na}_{2} \mathrm{HPO}_{4}, 2 \mathrm{H}_{2} \mathrm{O}$ & 2.20 & $12.4 \times 10^{-3}$ \\
\hline $\mathrm{KH}_{2} \mathrm{PO}_{4}$ & 1.75 & $12.9 \times 10^{-3}$ \\
\hline $\mathrm{MgSO}_{4}, 7 \mathrm{H}_{2} \mathrm{O}$ & 0.25 & $1.01 \times 10^{-3}$ \\
\hline $\mathrm{CaCl}_{2}, 2 \mathrm{H}_{2} \mathrm{O}$ & 0.25 & $1.7 \times 10^{-3}$ \\
\hline Trace element solution & $1.25 \mathrm{~mL} . \mathrm{L}^{-1}$ & \\
\hline \multicolumn{3}{|c|}{ Trace element solution: } \\
\hline Product & $\begin{array}{c}\text { Concentration } \\
\left(\mathrm{g} \cdot \mathrm{L}^{-1}\right)\end{array}$ & $\begin{array}{l}\text { Concentration } \\
\left(\mathrm{mol}^{\left.-\mathrm{L}^{-1}\right)}\right.\end{array}$ \\
\hline $\mathrm{CaCl}_{2}, 2 \mathrm{H}_{2} \mathrm{O}$ & 7.34 & $49.9 \times 10^{-3}$ \\
\hline $\mathrm{MgCl}_{2}, 6 \mathrm{H}_{2} \mathrm{O}$ & 25.07 & $123 \times 10^{-3}$ \\
\hline $\mathrm{FeCl}_{3}, 6 \mathrm{H}_{2} \mathrm{O}$ & 4.8 & $17.8 \times 10^{-3}$ \\
\hline $\mathrm{MnCl}_{2}, 4 \mathrm{H}_{2} \mathrm{O}$ & 1.03 & $5.21 \times 10^{-3}$ \\
\hline $\mathrm{ZnCl}_{2}, 2 \mathrm{H}_{2} \mathrm{O}$ & 0.01 & $0.058 \times 10^{-3}$ \\
\hline $\mathrm{CuCl}_{2}, 2 \mathrm{H}_{2} \mathrm{O}$ & 0.112 & $0.66 \times 10^{-3}$ \\
\hline $\mathrm{NaMoO}_{4}, 2 \mathrm{H}_{2} \mathrm{O}$ & 0.0025 & $0.0133 \times 10^{-3}$ \\
\hline
\end{tabular}

tried several inclination angles, and found that the mass of biofilm left on the membrane was decreased when increasing the angle from 0 to $45^{\circ}$ by steps of $15^{\circ}$, without the biomass slipping away. Beyond $45^{\circ}$, we observed some biomass flowing down and therefore decided to run all experiments at $45^{\circ}$. The coupon was then weighted, let for drying for $24 \mathrm{~h}$ at $105^{\circ} \mathrm{C}$ and weighted again. A control experiment with a membrane coupon but no biofilm allowed accounting for the weight loss of the membrane material in the drying conditions.

Considering that the biofilm is essentially made of water, the biofilm thickness of a coupon can be estimated from Eq. (5)

$t_{\mathrm{bf}}=\frac{m_{\mathrm{i}}-m_{\mathrm{f}}}{\rho_{\mathrm{w}} \cdot A_{\mathrm{s}}}$

Where $t_{\mathrm{bf}}$ is the average biofilm thickness of the coupon, $m_{\mathrm{i}}$ and $m_{\mathrm{f}}$ are the sample masses of coupons (biofilm + membrane) before and after drying the biofilm respectively. The difference $m_{\mathrm{i}}-m_{\mathrm{f}}$ represents the mass of water (which is the main biofilm constituent (Sutherland, 2001)) evaporated during the drying process. Dividing $m_{\mathrm{i}}-m_{\mathrm{f}}$ by $\rho_{\mathrm{w}} \cdot A_{\mathrm{s}}$, we obtain an estimation of the biofilm thickness. By neglecting the mass of dry matter in the biofilm, we make an error of c.a. $5 \%$. The thickness given in the figures is the average over 18 coupons and accounts for the heterogeneity of the biofilm over the total membrane area.

We should acknowledge here that the actual shape of the biofilm in operation is probably mostly uneven, with streamers developing toward the flow channel. Therefore the thickness we derive from our experimental procedure is an average of this structure over an area of several square centimeters of biofilm. This is however well adapted to the concept of global mass transfer coefficient used in this approach.

The quantity of dry matter found in a volume of wet biofilm, $\rho_{\mathrm{bf}}\left(\mathrm{kg} \mathrm{m}^{-3}\right)$ is obtained as follows (Wäsche et al., 2002):

$\rho_{\mathrm{bf}}=\frac{m_{\mathrm{f}}-m_{\mathrm{mb}}}{m_{\mathrm{i}}-m_{\mathrm{mb}}} \cdot \rho_{\mathrm{w}}$

where $m_{\mathrm{mb}}$ is the mass of a virgin membrane's coupon.

\section{Results and discussion}

\subsection{Transfer through the system without biofilm}

We report in Fig. 3a and $b$ the mass transfer coefficients of neon as measured through the membrane in the absence of biofilm. From Fig. 3a, it is clear that in our experimental condition the mass transfer resistance in the gas phase is negligible compared to the membrane and liquid resistances, whereas Fig. $3 \mathrm{~b}$ shows an important resistance of the liquid phase in the transfer of gas through the system \{liquid, membrane, gas\}. This means that a mass transfer limitation may exist at the biofilm-liquid interface over the range of Reynolds numbers covered in this study.

The resistance in series standard model (Eq. (7)) was adapted from Gabelman and Hwang (1999).

$\frac{1}{\mathrm{~K}_{\mathrm{G}}}=\frac{1}{\mathrm{H}^{\prime} \cdot k_{\text {gas }}}+\frac{1}{\mathrm{H}^{\prime} \cdot k_{\text {membrane }}}+\frac{1}{k_{\text {liquid }}}$

Where $k_{\text {gas }}, k_{\text {membrane }}$ and $k_{\text {liquid }}$ are the local mass transfer coefficients of the gas phase, the membrane and the liquid 


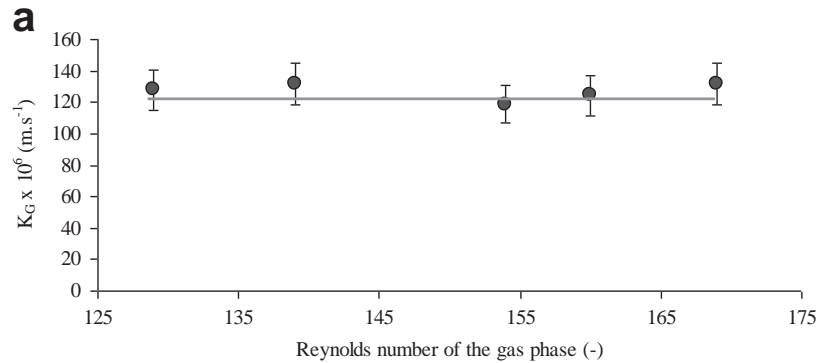

b

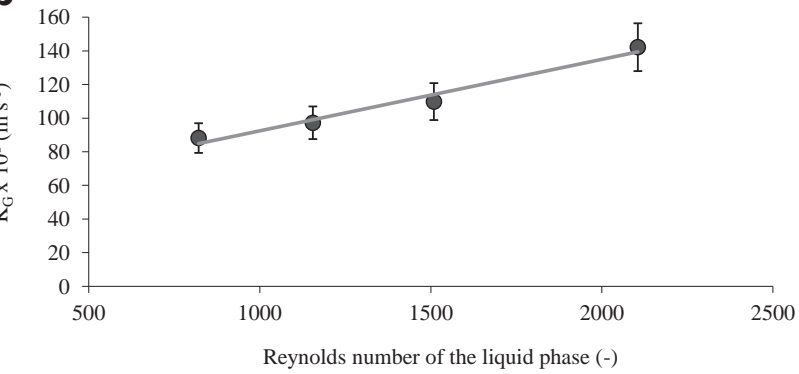

Fig. 3 - a: The Reynolds number in the gas phase has no influence on the global mass transfer coefficient $\left(K_{G}\right)$ in the range investigated. The Reynolds number in the liquid phase was kept constant and equal to 1890 (Picard, 2011). b: A significant increase in mass transfer $\left(K_{G}\right)$ was observed when the Reynolds number in the liquid phase was increased from 700 to 3200 . The Reynolds number in the gas phase was kept constant at 130 (Picard, 2011).

phase respectively $\left(\mathrm{m} \mathrm{s}^{-1}\right)$. $\mathrm{H}^{\prime}$ is the dimensionless Henry law's constant (Lide and Frederikse, 1995). 1/ $k_{\text {gas }}$ was neglected as explained above.

The mass transfer coefficient in the liquid boundary layer $k_{\text {liquid }}$ can be obtained in a general form according to Eq. (8) (Gabelman and Hwang, 1999).

$\mathrm{Sh}=\beta \cdot \operatorname{Re}^{\alpha} \cdot \mathrm{Sc}^{0.33}$

In Eq. (8), $\alpha$ and $\beta$ are two constants, $S h$ is the Sherwood number, Re is the Reynolds number and Sc is the Schmidt number.

By combination of Eqs. (7) and (8), and accounting for the fact that the mass transfer coefficient in the gas phase is high, one can write:

$\frac{1}{\mathrm{~K}_{\mathrm{G}}}=\frac{1}{\mathrm{H}^{\prime} \cdot k_{\text {membrane }}}+\frac{1}{\mathrm{C} \cdot \mathrm{Re}^{\alpha}}$

$C$ is a constant.

By fitting this Eq. (9) to our experimental results obtained for various values of the Reynolds number, we could determine the membrane mass transfer coefficient, $k_{\text {membrane }}$ and the coefficients $\alpha$ and $\beta$. Eventually, we end up with Eq. (10) which describes the mass transfer coefficient through the system in the absence of biofilm:

$\mathrm{Sh}=0.024 \cdot \mathrm{Re}^{0.55} \cdot \mathrm{Sc}^{0.33}$

The method used for fitting Eq. (9) to our results is as described in Gabelman and Hwang (1999).

We then found an estimation of the mass transfer coefficient through the pristine membrane equals to $5 \cdot 10^{-2} \mathrm{~ms}^{-1}$.
This value is several orders of magnitude larger than $K_{G}$ in any of our experimental conditions. This large value of $k_{\text {membrane }}$ confirmed that the membrane pores are filled with gas as expected since we used a hydrophobic membrane. Then, this value is compared below with the value found for a membrane after a biofilm has been grown on it.

\subsection{Transfer through the system with biofilm}

The growth of a biofilm on a membrane is meant to change its properties, by adsorption of bacteria or their exopolysaccharides (EPS) on its surface or inside its porous network. In order to evaluate the influence of fouling on the global mass transfer coefficient $K_{G}$, the flux of neon through a membrane supporting a biofilm has been measured for two values of the Reynolds number (400 and 1400). In both cases, $K_{G}$ was reduced by a factor of 3 as compared to the value found without biofilm. Then, in order to check if the change in resistance was located in the biofilm or at the membrane surface, the biofilm was removed from the membrane using a lab spoon, leaving absorbed cells, proteins and EPS, and the flux of neon was measured again. Knowing the mass transfer resistance of the liquid phase and using the resistance in series model (Eq. (11)), we could obtain a value for the resistance of each phase and its contribution to the global resistance.

$\frac{1}{K_{\mathrm{G}}^{\text {biofilm }}}=\frac{1}{H^{\prime} \cdot k_{\text {gas }}}+\frac{1}{H^{\prime} \cdot k_{\text {membrane }}^{\text {used }}}+\frac{1}{k_{\text {biofilm }}}+\frac{1}{k_{\text {liquid }}}$

Where $K_{G}^{\text {biofilm }}$ is the global mass transfer coefficient in the presence of a biofilm ( $\left.\mathrm{m} \mathrm{s}^{-1}\right), k_{\text {biofilm }}$ is the mass transfer coefficient through the biofilm $\left(\mathrm{m} \mathrm{s}^{-1}\right)$ and $k_{\text {membrane }}^{\text {used }}\left(\mathrm{m} \mathrm{s}^{-1}\right)$ is the mass transfer coefficient of the membrane after the biofilm has been removed.

The results of the contribution of each phase to the global mass transfer coefficient are summarized in Fig. 4, where one can see that in our conditions, the mass transfer resistance

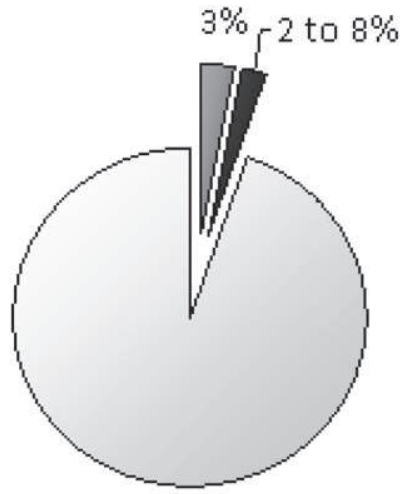

$\square$ Resistance of the liquid phase

Resistance of the used them brane

$\square$ Resistance of the biofilm

Fig. 4 - Contribution of the liquid phase (dark gray), fouled membrane (black) and biofilm (light gray) to the mass transfer resistance. The biofilm was grown in conditions of run \#4 (Table 1). The mass transfer measurements on the fouled membrane have been measured at low Reynolds number (c.a. 700): left; at high Reynolds number (c.a. 3000): right (Picard, 2011). 
was mainly located in the biofilm, whatever the hydrodynamic conditions and the level of membrane fouling. We found that the fouled membrane resistance was larger than the clean membrane one, though negligible as compared to the biofilm resistance. It was of the same order of magnitude as the resistance of the liquid boundary layer, but small as compared to the resistance we would find if the membrane pores were filled with water. This suggests that the pores of the fouled membranes where still at least partially full of gas, and that the adsorbed layer of cells and EPS offers a significant resistance to the transfer of neon.

\subsection{Dry matter of the biofilm as a function of hydrodynamics}

In our conditions, we could check (Fig. 5) that the dry matter content of the biofilm was almost not changed when varying the hydrodynamic conditions (the range of shear stress spans over one decade). A slight increase from 70 to $90 \mathrm{~kg} \mathrm{~m}^{-3}$ (i.e. 7-9\%) can be observed. This slight increase is consistent with the images obtained by confocal microscopy (Leica, DMRXA2), shown in Fig. $7 a$ and $b$. This quite low dry matter content indicates that the volume available for molecular diffusion inside the biofilm is large. The average porosity of the biofilm is then probably around $91-93 \%$.

\subsection{Effective diffusivity in the biofilm}

With the global mass transfer coefficient through the biofilm, one can calculate the corresponding apparent diffusivity of neon through the biofilm $D_{\mathrm{bf}}$ as the product $k_{\mathrm{biofilm}} \cdot t_{\mathrm{bf}} \cdot k_{\mathrm{biofilm}}$ is so small compared to $k_{\text {liquid }}, k_{\text {gas }}$ and $k_{\text {membrane }}^{\text {used }}$ that one can use $K_{G}^{\text {biofilm }}$ instead to calculate $D_{\text {eff. }}$ The effective diffusivity $D_{\text {eff }}$ of the gas through the biofilm was then calculated according to Stewart (1998), as the ratio of the apparent diffusivity $D_{\text {bf }}$ by the gas diffusivity in water $D_{\infty}$ (Eq. (12)).

$D_{\text {eff }}=\frac{K_{G}^{\text {biofilm }} \cdot t_{b f}}{D_{\infty}}$

$D_{\text {eff }}$ is a dimensionless number. As the determination of $K_{G}$ assumes a pure diffusive transfer, if its value is larger than 1 , this suggests that another transport mechanism than diffusion interferes in the transport mechanism.

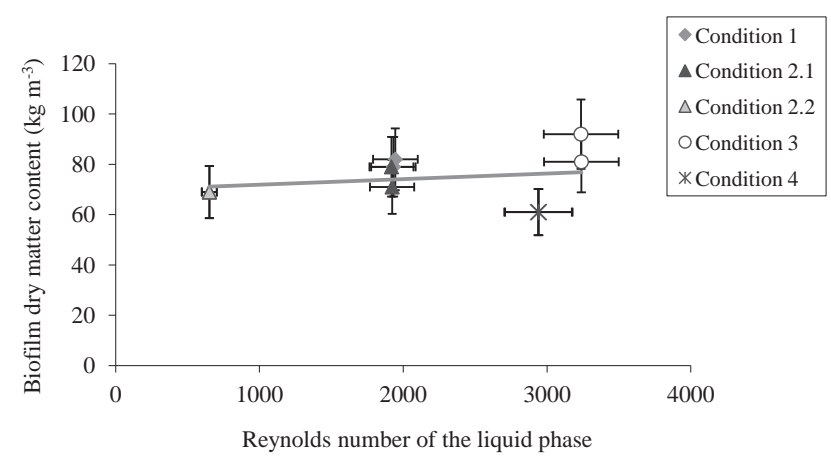

Fig. 5 - Amount of dry matter found per unit of biofilm volume as a function of the Reynolds number in the liquid phase (Picard, 2011).
The data on effective diffusion coefficients have been plotted in Fig. 6 versus the Reynolds number. These data show that diffusion seems to be independent from the flow through the open liquid channel for Reynolds numbers ranging from 700 to 3000 . Within this range of conditions, the effective diffusion coefficient is about $60 \%$ of the coefficient in plain water. The mean porosity to tortuosity ratio of the biofilm would then be around 0.6. Considering this value, the average porosity found in Section 3.3 and the increase in resistance of the used membrane commented in Section 3.2, suggests that the biofilm growth creates two types of resistive structures at the surface of the membrane:

- a thin, rather dense layer immediately deposited at the membrane surface and maybe partly invading the pores, and which remains sticked to the membrane when one scratches it with a lab spoon

- a thicker, one with a low dry matter content and hence a high porosity and through which gases and nutrients diffuse almost as in water.

A sharp increase in effective diffusivity was observed beyond 3000, and the effective diffusion was then larger than 1. Another mechanism than Brownian motion must then combine to it, and the results reported in the literature suggest that this supplementary transport phenomenon would be dispersion generated by the convection through the biofilm induced by the cross-flow along the biofilm surface. This convection would occur in the most porous part of the biofilm.

\subsection{Convection inside the biofilm}

One of the questions at this stage is to know if the conditions are met for convection to occur within the biofilms grown in our experiments. An accumulation of biofilm sections obtained by confocal microscopy is shown in Fig. 7a where one can see the existence of cavities.

Then, we have developed a simple model based on the assumption that the pressure in a plane normal to the main flow direction is the same in the biofilm and in the liquid

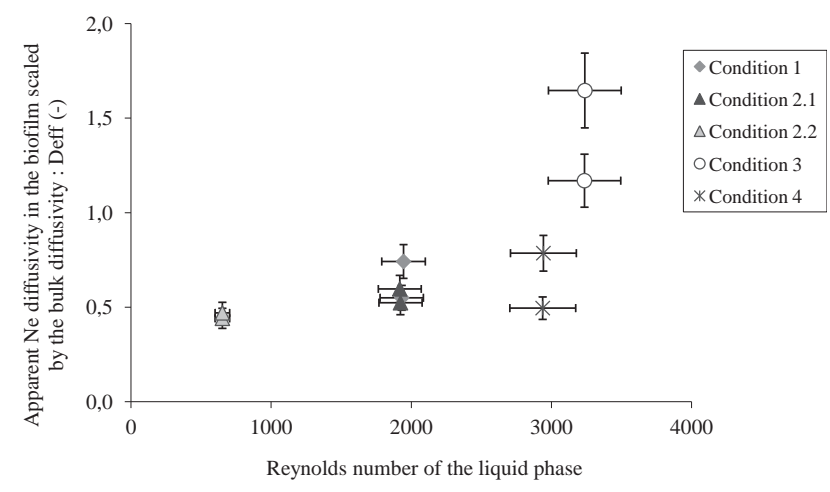

Fig. 6 - Effective diffusion coefficient of neon through biofilms as a function of the Reynolds number in the liquid phase. A sharp increase in mass transfer is observed around $\operatorname{Re}=3000$, although we show (Fig. 3) that the major transfer resistance is located within the biofilm (Picard, 2011). 

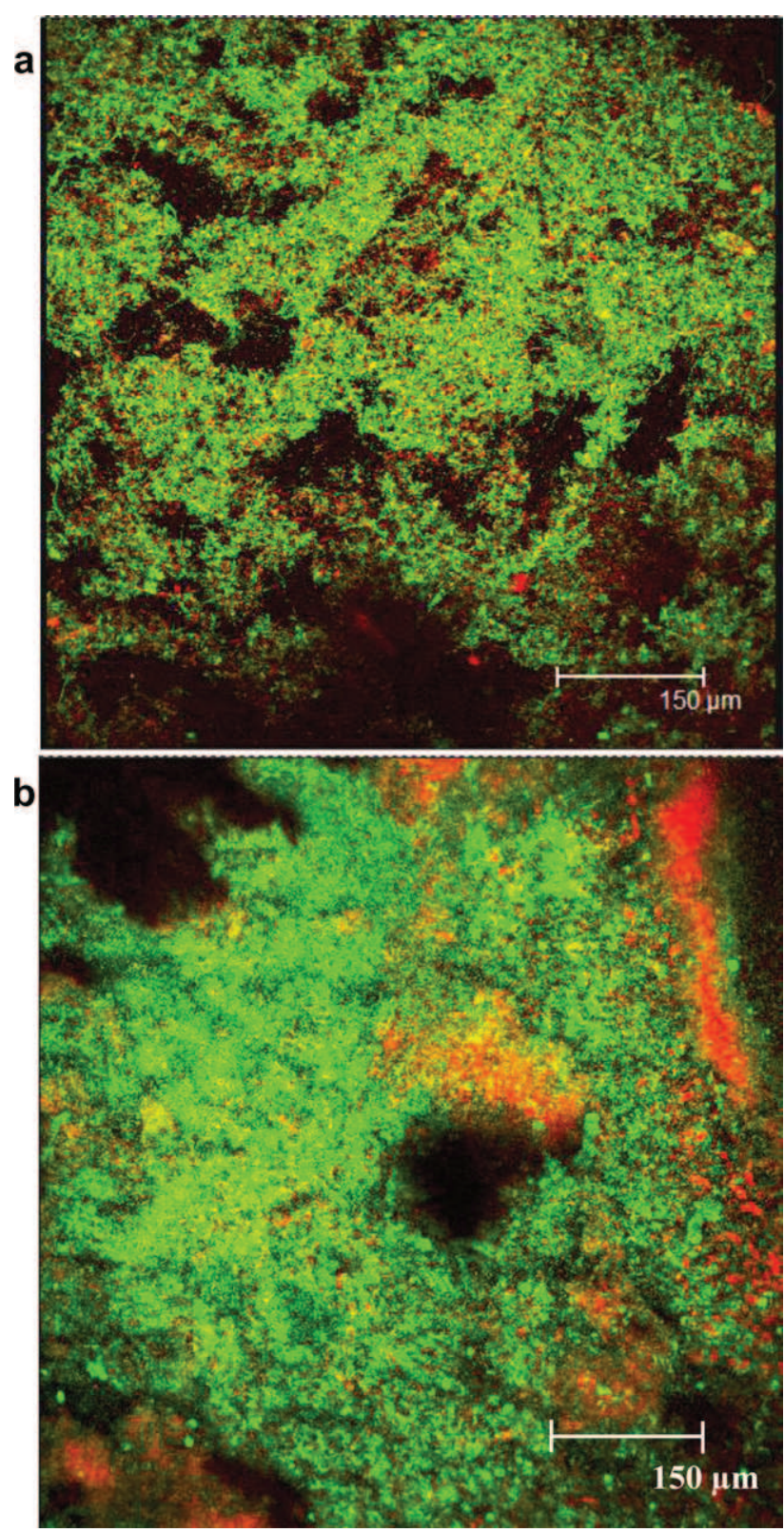

Fig. 7 - a: Projection of several confocal images. The pictures are taken by step of $5 \mu \mathrm{m}$ across the depth of the biofilm. SYTO 9 colored in green all the bacterias, propidium iodide colored in red dead bacterias. The sum of green and red bacterias is yellow (Picard, 2011). b: Confocal image of the biofilm at $620 \mu \mathrm{m}$ depth. SYTO 9 colored in green all the bacterias, propidium iodide colored in red dead bacterias. The sum of green and red bacterias is yellow (Picard, 2011). (For interpretation of the references to color in this figure legend, the reader is referred to the web version of this article.)

channel. For a given flow rate, we can calculate the pressure drop, $\Delta P$, using the Hagen-Poiseuille model.

$\Delta \mathrm{P}=\frac{12 \cdot \mu \cdot \mathrm{V} \cdot \mathrm{L}}{t_{\mathrm{c}}^{2}}$
Where $\mathrm{V}$ is the average velocity in the liquid channel $\left(\mathrm{m} \mathrm{s}^{-1}\right)$, $\mu$ is the viscosity (Pa s), $L$ the channel length $(\mathrm{m})$ and $t_{\mathrm{c}}$ is the channel thickness $(\mathrm{m})$.

Inside the biofilm cavities, the velocity of the liquid driven by this pressure drop can be approached by the Darcy law:

$v_{\mathrm{bf}}=\frac{\Delta \mathrm{P}}{R_{\mathrm{h}}}$

The hydraulic resistance of the biofilm $R_{\mathrm{h}}$ is proportional to amount of biofilm to be flowed through:

$R_{\mathrm{h}}=\alpha \cdot \mathrm{M}_{\mathrm{d}}$

Where, $\alpha$ is the specific hydraulic resistance, $M_{d}$ is the mass in dry matter per unit area $\left(\mathrm{kg} \mathrm{m}^{2}\right)$. It can be simply obtained as:

$M_{\mathrm{d}}=L \cdot(1-\varepsilon) \cdot \rho_{\mathrm{bf}}$

where $\varepsilon$ is the biofilm porosity and $\rho_{\text {bf }}$ the average dry matter of the biofilm material. An estimate of $\alpha$ is given by the Kozeny-Carman equation:

$\alpha=\frac{5 \cdot(1-\varepsilon) \cdot a_{\mathrm{p}}^{2}}{\varepsilon^{3} \cdot \rho}$

$a_{\mathrm{p}}$ is the specific area of the particles forming the porous bed. For hard spheres of radius $r, a_{\mathrm{p}}=3 / r$.

A combination of Eqs. (13)-(17) then allows deriving $v_{\mathrm{bf}}$ as a function of the average liquid flow velocity and the biofilm parameters:

$v_{\mathrm{bf}}=\frac{12 \cdot \mathrm{V} \cdot \varepsilon^{3}}{5 \cdot t_{\mathrm{c}}^{2} \cdot(1-\varepsilon)^{2} \cdot a_{\mathrm{p}}^{2}}$

Using confocal microscopy images (not shown here), at a depth of $620 \mu \mathrm{m}$ from biofilm surface, we determined an average pore radius, l, of $200 \mu \mathrm{m}$. This is in agreement with De Beer and Stoodley (1995) who have grown a conventional heterotrophic aerated biofilm and found an average pore dimension of $150 \mu \mathrm{m}$. We can therefore calculate the axial Peclet number via Eq. (1) using the average pore radius as the hydraulic diameter of the channels.

We assume that the biofilm hydraulic porosity is close to 91-93\% in the calculation of $v_{\mathrm{bf}}$ using Eq. (18). The channel thickness in this case was $8 \mathrm{~mm}$ with a biofilm thickness of c.a. $1.5 \mathrm{~mm}$, so $t_{c}$ was taken equal to $6.5 \mathrm{~mm}$. We then used Eq. (18) to estimate the average flow velocities in our biofilms, although part of our conditions extend beyond the laminar regime for which the Hagen-Poiseuille flow is strictly valid and we found:

$v_{\mathrm{bf}}=0.018 \cdot \mathrm{V}$

Based on this result, a validation of the assumption of the pressure being the same over a plane normal to the main flow is proposed in the Appendix at the end of this paper.

The calculated velocity induced in the biofilm by a crossflow outside the biofilm of $0.14 \mathrm{~m} \mathrm{~s}^{-1}$ is $2.6 \mathrm{~mm} \mathrm{~s}^{-1}$. $v_{\mathrm{bf}}$ is of the order of a few percents of $V$, therefore the flow profile in the liquid channel is probably not disturbed by the flow through the biofilm. These orders of magnitude are consistent with those published by Stoodley et al. (1994) and De Beer and Stoodley (1995) and support the assumption of transport phenomena within the biofilm enhanced by convection in our conditions. 


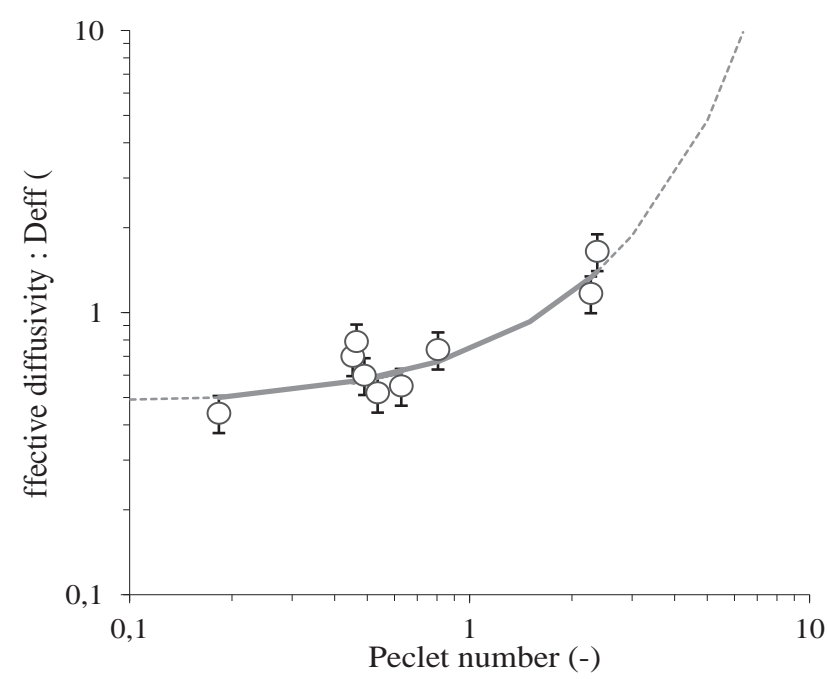

Fig. 8 - Experimental effective diffusion coefficient of neon as a function of the Peclet number (Eq. (1)). The velocity of liquid in the channels of the biofilm is estimated using Eq. (16), and its average porosity from the effective diffusivity at low Reynolds number. The results are then compared with those of Aspa et al. (2011) (Curve) (Picard, 2011).

\subsection{Convection and effective diffusivity}

The effective diffusion coefficient was then plotted versus the Peclet number in Fig. 8. The shape is similar to the one in Fig. 6 as the Peclet and Reynolds numbers are proportional to each other. The value for the transition Peclet number depends on the values of the parameters one uses to calculate the Peclet number. Within the present assumptions, the transition would occur for a Peclet number around 1, whereas Aspa et al. (2011) found transitions around 10 to 100, depending on the flux directions considered. In any case, it seems that a biofilm should be operated in such conditions that the Peclet number is beyond the transition value, so as to be able to enhance the mass transfer by increasing the cross-flow velocity, or far below this transition so as to save the pumping energy.

\section{Conclusion}

The transfer through a heterotrophic aerated biofilm supported on a porous membrane is mainly limited by the biofilm itself, even when the membrane has been heavily fouled. A mass transfer enhancement is experimentally observed when the cross-flow over the biofilm surface exceeds some particular value. In accordance to the predictions by Aspa et al. (2011) this enhancement can be analyzed as a radial dispersion created by the convective flow induced by the cross-flow. Such dispersion occurs only for Peclet number values beyond one threshold. Because the calculation of the Peclet number involved various assumptions on the biofilm channel size, we cannot conclude on an absolute value of this threshold. However an analytical equation derived in the present work shows that the average flow through the biofilm would be proportional to the average cross-flow velocity.

\section{Acknowledgments}

The authors wish to thank "Veolia Environnement Recherche \& Innovation" for supporting this project, Dr. Eoin Syron for discussion and Mr. Jean-Christophe Rouch for technical assistance.

\section{Appendix}

In order to compare the pressure drop in the radial and in the axial direction in the biofilm, one can estimate the average radial convective velocity in the biofilm. Observing that the apparent maximum mass flux is twice as large as the pure diffusive flux across the biofilm, one can ascribe this difference to a convective velocity in the radial direction, $v_{\mathrm{c}, \mathrm{r}}$. We can calculate an estimate of the rate of diffusion in the radial direction $v_{\mathrm{d}, \mathrm{r}}$ as the ratio of the effective diffusivity by the biofilm thickness $t_{\mathrm{bf}}$ :

$v_{\mathrm{d}, \mathrm{r}}=\frac{D_{\text {eff }} \cdot D_{\infty}}{t_{\mathrm{bf}}}$

In our conditions, the maximum value $D_{\text {eff }}$ for was 1.2, whereas at low Re (low Pe), $D_{\text {eff }}=0.5$. One can then get an estimate of the radial convective velocity as:

$v_{\mathrm{c}, \mathrm{r}}=\frac{1.2 \cdot D_{\infty}}{t_{\mathrm{bf}}}-\frac{0.5 \cdot D_{\infty}}{t_{\mathrm{bf}}}=\frac{0.7 \cdot D_{\infty}}{t_{\mathrm{bf}}}$

With, for Neon in water, $D_{\infty}=3.6 \cdot 10^{-9} \mathrm{~m}^{2} \mathrm{~s}^{-1}, \mathrm{t}_{\mathrm{bf}}=10^{-3} \mathrm{~m}$, one finds $v_{\mathrm{c}, \mathrm{r}}=2.5 \cdot 10^{-6} \mathrm{~m}^{2} \mathrm{~s}^{-1}$. Considering Eq. (18) in the manuscript, for our conditions, the average axial velocity in the biofilm is:

$\mathrm{V}_{\mathrm{bf}}=0.18 \cdot \mathrm{V}$

At its maximum, the average axial velocity in the channel, $\mathrm{V}$, is $0.14 \mathrm{~m} \mathrm{~s}^{-1}$, then the maximum value for $v_{\mathrm{bf}}$ in our conditions is $2 \cdot 10^{-3} \mathrm{~m} \mathrm{~s}^{-1}$.

If one considers, as a first approximation that the porosity in the biofilm is isotropic, then the ratio of the pressure drops in the radial and axial directions due to convection in the biofilm, is the same as the ratio of the radial and axial velocities, $v_{\mathrm{c}, \mathrm{r}} / v_{\mathrm{bf}}$. The order of magnitude of this ratio is, according to the calculations described here above, of about $1.25 \cdot 10^{-3}$.

One can then conclude that the pressure drop in the radial direction is negligible as compared to the pressure drop in the axial direction, and therefore that the pressure is the same, in a first approximation, at any point of a radial plane.

\section{R E F E R E N C ES}

Aspa, Y., Debenest, G., Quintard, M., 2011. Effective dispersion in channelled biofilms. International Journal of Environment and Waste Management 7 (1-2), 112-131. 
Beyenal, H., Lewandowski, Z., 2000. Combined effect of substrate concentration and flow velocity on effective diffusivity in biofilms. Water Research 34 (2), 528-538.

Beyenal, H., Lewandowski, Z., 2002. Internal and external mass transfer in biofilms grown at various flow velocities. Chemical Engineering Progress 18 (1), 55-61.

Bougard, D., Bernet, N., Chèneby, D., Delgenès, J.P., 2006. Nitrification of a high strength wastewater in an inverse turbulent bed reactor: effect of temperature on nitrite accumulation. Process Biochemistry 41 (1), 106-113.

Chung, J., Li, X., Rittmann, B.E., 2007. Bio-reductive dechlorination of 1,1,1-trichloroethane and chloroform using a hydrogenbased membrane biofilm reactor. Biotechnology and Bioengineering 97 (1), 52-60.

De Beer, D., Stoodley, P., 1995. Relation between the structure of an aerobic biofilm and transport phenomena. Water Science and Technology 32 (8), 11-18.

Emanuelsson, E.A.C., Livingston, A.G., 2004. Overcoming oxygen limitations in membrane-attached biofilms - investigation of flux and diffusivity in an anoxic biofilm. Water Research 38 (6), 1530-1541.

Gabelman, A., Hwang, S.T., 1999. Hollow fibre membrane contactors. Journal of Membrane Science 159 (1-2), 61-106.

Garcia Lopez, L.A., Veiga, M.C., Nogueira, R., Aparicio, A., Melo, L.F., 2003. A technique using membrane flow cell to determine average mass transfer coefficients and tortuosity factors in biofilms. Water Science and Technology 47 (5), $61-67$.

Kugaprasatham, S., Nagaoka, H., Ohgaski, S., 1992. Effect of turbulence on nitrifying biofilms at non limiting substrate conditions. Water Research 26 (12), 1629-1638.

Kwok, W.K., Picioreanu, C., Ong, S.L., Van Loosdrecht, M.C.M., Ng, W.J., Heijnen, J.J., 1998. Influence of biomass production and detachment forces on biofilm structures in a biofilm airlift suspension reactor. Biotechnology and Bioengineering 58 (4), 400-407.

LaPara, T.M., Cole, A.C., Shanahan, J.W., Semmens, M.J., 2006. The effects of organic carbon, ammoniacal-nitrogen, and oxygen partial pressure on the stratification of membrane-aerated biofilms. Journal of Industrial Microbiology \& Biotechnology 33 (4), 315-323.
Lee, K.C., Rittmann, B.E., 2002. Applying a novel autohydrogenotrophic hollow-fiber membrane biofilm reactor for denitrification of drinking water. Water Research 36 (8), 2040-2052.

Lide, D.R., Frederikse, H.P.R., 1995. Handbook of Chemistry and Physics, seventy-sixth ed. CRC Press Inc., Boca Raton, FL.

Matsumoto, S., Terada, A., Tsuneda, S., 2007. Modelling of membrane-aerate biofilm: effect of $\mathrm{C} / \mathrm{N}$ ratio, biofilm thickness and surface loading of oxygen on feasibility of simultaneous nitrification and denitrification. Biochemical Engineering Journal 37 (1), 98-107.

Melo, L.F., 2005. Biofilm physical structure, internal diffusivity and tortuosity. Water Science and Technology 52 (7), 77-84.

Nerenberg, R., Kawagoshi, Y., Rittmann, B.E., 2007. Microbial ecology of a perchlorate-reducing, hydrogen-based membrane biofilm reactor. Water Research 42 (4-5), 1151-1159.

Pankhania, M., Brindle, K., Stephenson, T., 1999. Membrane aeration bioreactors for wastewater treatment: completely mixed and plug-flow operation. Chemical Engineering Journal 73 (2), 131-136.

Picard C. 2011. Transfert de matière dans un biofilm aéré sur membrane. Thesis, Université Paul Sabatier, Toulouse, France.

Stewart, P.S., 1998. A review of experimental measurements of effective diffusive permeabilities and effective diffusion coefficients in biofilm. Biotechnology and Bioengineering 59 (3), 261-272.

Stoodley, P., De Beer, D., Lewandowski, Z., 1994. Liquid flow in biofilm systems. Applied and Environmental Microbiology 60 (8), 2711-2716.

Sutherland, I.W., 2001. Biofilm exopolysaccharides: a strong and sticky framework. Microbiology 147, 3-9.

Syron, E., Casey, E., 2008. Model-based comparative performance analysis of membrane aerated biofilm reactor configuration. Biotechnology and Bioengineering 99 (6), 1361-1373.

Terada, A., Kaku, S., Matsumoto, S., Tsuneda, S., 2006. Rapid autohydrogenotrophic denitrification by a membrane biofilm reactor equipped with a fibrous support around a gas permeable membrane. Biochemical Engineering Journal 31 (1), 84-91.

Wäsche, S., Horn, H., Hempel, D.C., 2002. Influence of growth conditions on biofilm development and mass transfer at the bulk/biofilm interface. Water Research 36 (19), 4775-4784. 